\title{
Miniaturization of Ultra Low Profile Inverted L Antenna on Rectangular Conductor
}

\author{
Mitsuo Taguchi* Keisuke Kozaki \\ Dept. of Electrical \& Electronic Engineering \\ Nagasaki University \\ Nagasaki, Japan \\ *mtaguchi@nagasaki-u.ac.jp
}

\begin{abstract}
The ultra low profile inverted L antenna, whose horizontal element is bent as a meander line shape, is proposed and numerically analyzed for the reception antenna for the keyless entry system of automobiles at $315 \mathrm{MHz}$ band. In the case of the conducting plane of $70 \mathrm{~mm}$ by $350 \mathrm{~mm}$ and the antenna height of $31.7 \mathrm{~mm}$, the directivity of $2.48 \mathrm{dBi}$ is obtained. In the numerical analysis, the electromagnetic simulator WIPL-D based on the Method of Moment is used.
\end{abstract}

Keywords-low profile anetnna; keyless entry system; unbalanced fed inverted L anenna; WIPL-D

\section{INTRODUCTION}

The keyless entry system is a system designed to remotely permit or deny access to automobiles. Most keyless entry systems work on $315 \mathrm{MHz}$ in North America and Japan, and $433.92 \mathrm{MHz}$ in Europe. In the keyless entry system, the electromagnetic wave transmitted from the key outside of car is weak and the strength of electromagnetic field varies within a car [1]. The authors have numerically investigated the electric field distribution within the hollow metallic rectangular parallelepiped with an aperture on its top when the horizontal polarized wave is radiated from the dipole antenna located near the parallelepiped $[2,3]$. Although the amplitude of horizontal component of electric field varies depending on the position of dipole antenna, the vertical component of electric field does not vanish in the small particular area. Therefore, it is desired to develop a small, high gain antenna for the reception antenna of the keyless entry system.

The authors proposed an unbalanced fed, ultra low profile inverted L antenna located on the rectangular conducting plane [4]. This antenna consists of a coaxial cable. The inner conductor of the coaxial cable is extended from the end of outer conductor, that is, this antenna is excited at the end of outer conductor. The antenna height is around one thirtieth of wavelength. The length of horizontal element of this antenna is around a quarter wavelength. The input impedance is easily matched to $50 \Omega$ by changing the feed point. In this antenna, the mutual coupling between the inverted $\mathrm{L}$ antenna and the conducting plane is strong and the current distribution on the conducting plane contributes to the radiation. In the case of the size of conducting plane is $0.245 \lambda$ ( $\lambda$ : wavelength) by $0.408 \lambda$, the maximum gain becomes $4.14 \mathrm{dBi}$ and the return loss bandwidth less than $10 \mathrm{~dB}$ is $2.7 \%$.

In this paper, the ultra low profile inverted $\mathrm{L}$ antenna, whose horizontal element is bent as a meander line shape, is proposed for the reception antenna for the keyless entry system of automobiles at $315 \mathrm{MHz}$ band. In the numerical analysis, the electromagnetic simulator WIPL-D based on the Method of Moment is used [5].

\section{ANALYTICAL MODEL}

Figure 1 shows the structure of the ultra low profile inverted $\mathrm{L}$ antenna on a rectangular conducting plane. Figure 2(a) shows the inverted $\mathrm{L}$ antenna with one-turn meander line. Figure 2(b) shows the inverted L antenna with two-turn meander line. In each figure, the structure of the antenna is optimized to satisfy that the return loss is less than $-10 \mathrm{~dB}$ at the frequencies from $312 \mathrm{MHz}$ to $315.25 \mathrm{MHz}$.

\section{RESULTS AND DISCUSSION}

The current distribution, the electric field radiation patterns at the frequency of $315 \mathrm{MHz}$ and the return loss characteristics of three antennas are shown in Fig. 3, 4 and 5, respectively. The parameters of conducting plane are fixed to $p x p=p x m=$ $100 \mathrm{~mm}$, pyp $=300 \mathrm{~mm}$, and pym $=50 \mathrm{~mm}$. The directivity of three antennas are as follows:

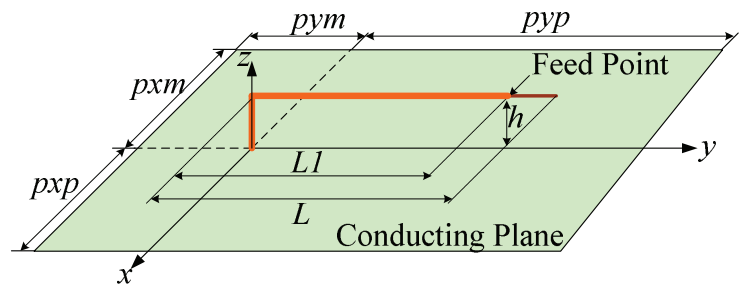

Figure 1. Unbalanced fed inverted $\mathrm{L}$ antenna. $h=31.7 \mathrm{~mm}(\lambda / 30), L=223.9 \mathrm{~mm}, L 1=173.5 \mathrm{~mm}, p x m=p x p=100 \mathrm{~mm}$, pym $=50 \mathrm{~mm}$, pyp $=300 \mathrm{~mm}$. 


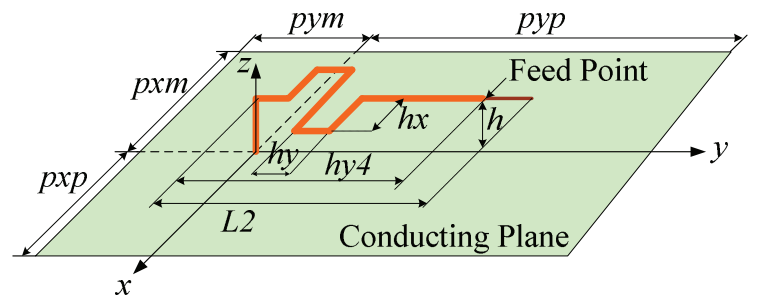

(a) Inverted $\mathrm{L}$ antenna with one turn meander line. $L 2=196.3 \mathrm{~mm}, h y 4=141.8 \mathrm{~mm}$.

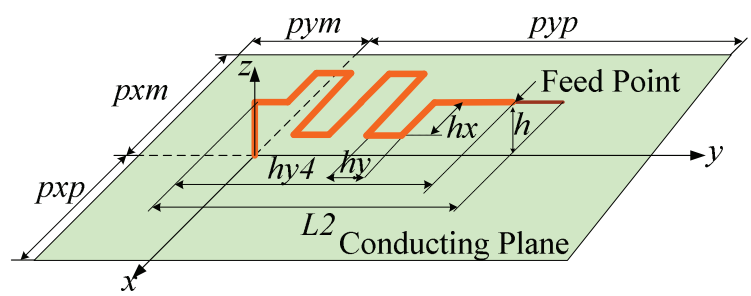

(b) Inverted $\mathrm{L}$ antenna with two turn meander line. $L 2=167.1 \mathrm{~mm}$, hy4 $=106.5 \mathrm{~mm}$.

Figure 2. Miniaturized inverted L antenna with meander line shaped horizontal element.

$h=31.7 \mathrm{~mm}(\lambda / 30), p x m=p x p=100 \mathrm{~mm}, p y m=50 \mathrm{~mm}, p y p=300 \mathrm{~mm}$, $h x=20 \mathrm{~mm}, h y=10 \mathrm{~mm}$.

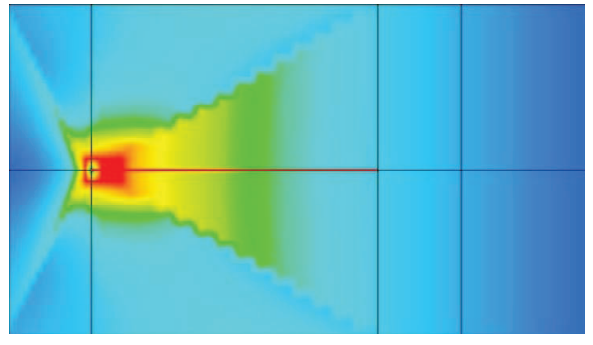

(a) Inverted L antenna.
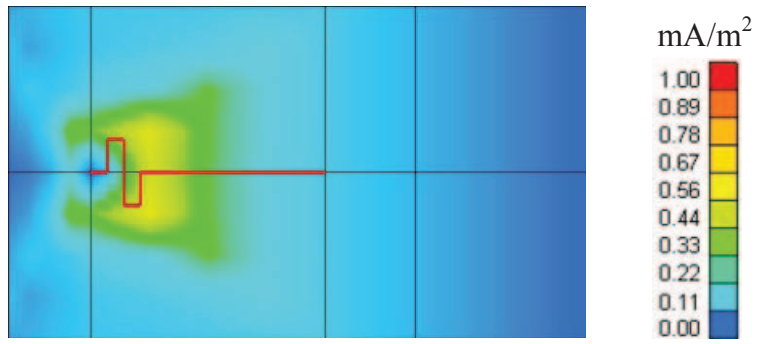

(b) Inverted L antenna with one turn meander line.

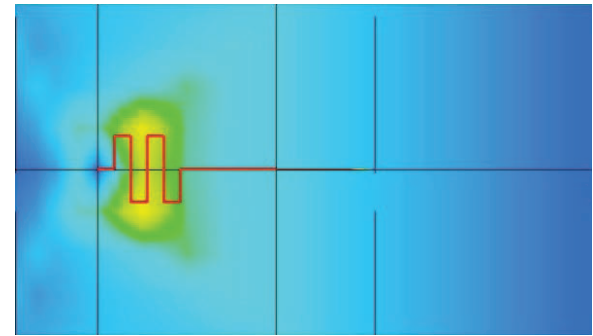

$\mathrm{mA} / \mathrm{m}^{2}$
1.00
0.89
0.78
0.67
0.56
0.44
0.33
0.22
0.11
0.00

(c) Inverted L antenna with two turn meander line. Figure 3. Current distribution at $315 \mathrm{MHz}$.

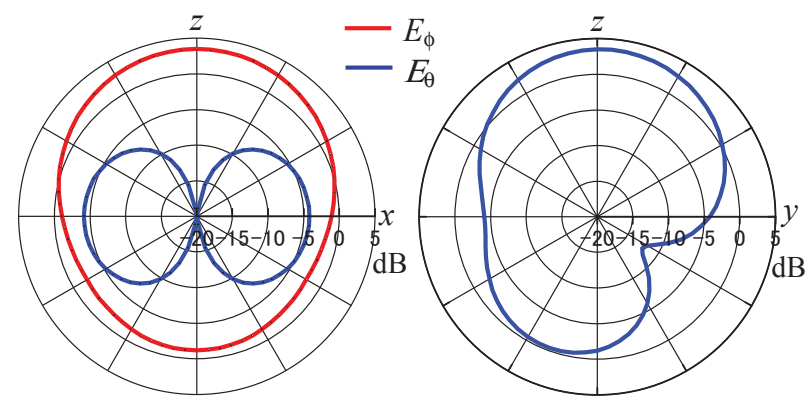

(a) Inverted L antenna.

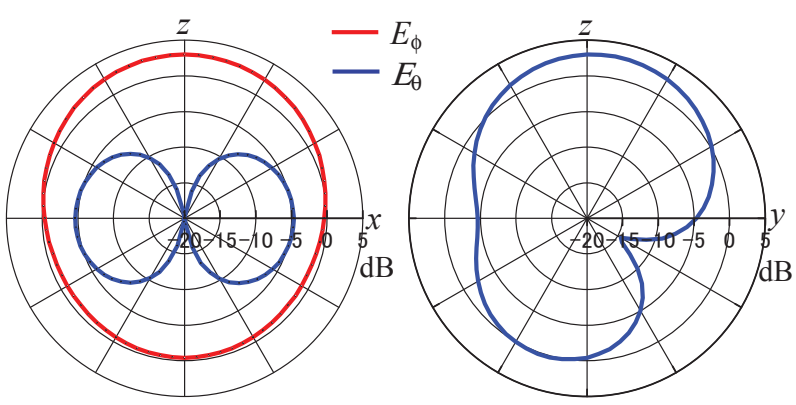

(b) Inverted L antenna with one turn meander line

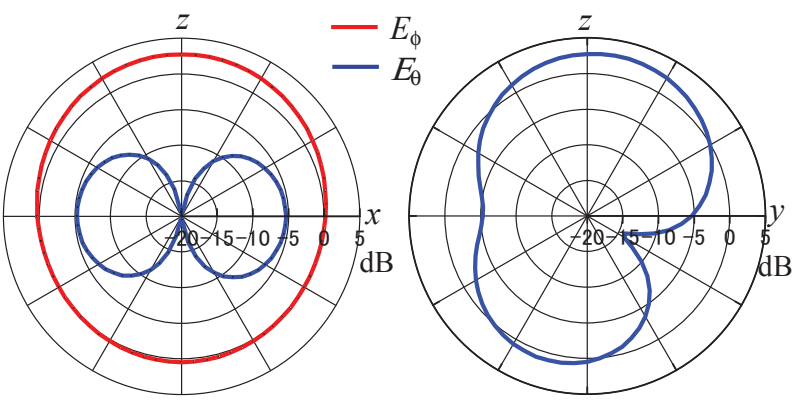

(c) Inverted L antenna with two turn meander line. Figure 4. Electric field radiation patterns at $3.15 \mathrm{GHz}$.

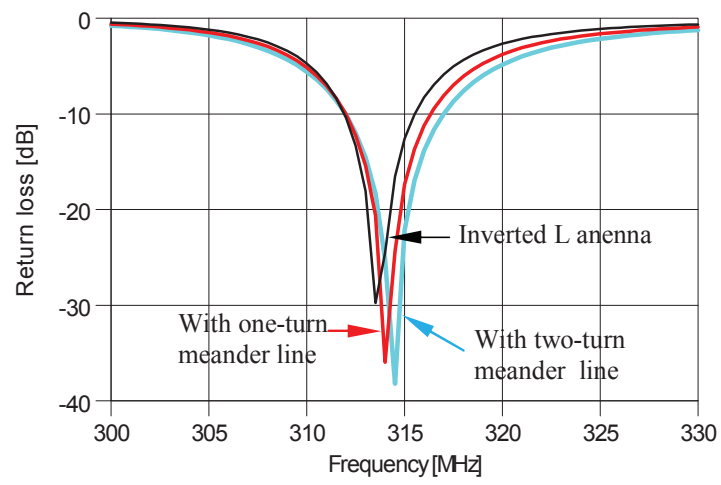

Figure 5. Return loss characteristics. 
Inverted L antenna (Fig. 1): $3.45 \mathrm{dBi}$

Inverted L antenna with one-turn meander line (Fig. 2(a)): $3.02 \mathrm{dBi}$

Inverted L antenna with two-turn meander line (Fig.2(b)): $2.80 \mathrm{dBi}$

As increasing the number of turns of meander line, the surface current on the conducting plane becomes weak. Therefore the return loss bandwidth becomes wider and the directivity becomes lower.

\section{A. Parameter Study}

In order to apply the inverted $\mathrm{L}$ antenna for the reception antenna of the keyless entry system, the smaller size of conducting plane is preferable. Since the directivity of the inverted L antenna with two-turn meander line is lower than that of the inverted L antenna with one-turn meander line, here, the return loss bandwidth and the directivity are investigated for the different geometry of antenna with one-turn meander line shown in Fig. 2(a). In all cases, hy 4 and $L 2$ are optimized to satisfy that the return loss is less than $-10 \mathrm{~dB}$ at the frequencies from $312 \mathrm{MHz}$ to $315.25 \mathrm{MHz}$.

Table I shows the antenna characteristics for different $h x$. On the conducting plane, the current distribution flows along the $y$ direction and concentrates around the base point of antenna. Therefore, when $h x$ becomes smaller, the directivity becomes higher.

Table II shows the antenna characteristics for different $h y$. As hy becomes longer, the phase difference between the currents on the $x$ directed element becomes larger. Then the surface current flowing along the $y$ direction on the conducting plane attenuates. This caused smaller directivity for longer $h y$.

Table III shows the antenna characteristics for different $p x m$ $=$ pxp. When the width of conducting plane becomes narrower, the mutual coupling between the inverted L antenna and the conducting plane becomes weak. Therefore the return loss bandwidth becomes wider and the directivity becomes lower as the pxm $=$ pxp becomes smaller.

Table IV shows the antenna characteristics for different $p y p$. As pyp becomes shorter, the reflected current at the end of conductor $x=$ pyp becomes larger. Then the directivity becomes smaller.

Table V shows the antenna characteristics for different pym. The phase of surface current flowing along the $y$ direction is controlled by the length of pym. When pym $=50 \mathrm{~mm}$, the surface current contributes to the radiation significantly.

TABLE I. RETURN LOSS BANDWISTH AND DIRECTIVITY FOR DIFFERENET $h x$.

\begin{tabular}{|c|c|c|c|c|c|}
\hline \multirow{2}{*}{$\begin{array}{c}h x \\
{[\mathrm{~mm}]}\end{array}$} & \multirow{2}{*}{$\begin{array}{c}\text { hy4 } \\
{[\mathrm{mm}]}\end{array}$} & \multirow{2}{*}{$\begin{array}{c}\mathrm{L2} \\
{[\mathrm{mm}]}\end{array}$} & \multicolumn{2}{|c|}{$\begin{array}{c}\text { Return loss bandwidth } \\
{[\mathrm{MHz}]}\end{array}$} & \multirow{2}{*}{$\begin{array}{c}\text { Direcitivity } \\
\text { at } 315 \mathrm{MHz} \\
{[\quad[\mathrm{dBi}]}\end{array}$} \\
\hline & & & Lower freq. & $\begin{array}{l}\text { Higher } \\
\text { freq. }\end{array}$ & \\
\hline 5 & 172.6 & 224.2 & 311.5 & 315.5 & 3.37 \\
\hline 20 & 141.7 & 196.3 & 311.4 & 315.7 & 3.02 \\
\hline 40 & 86 & 152.9 & 310.7 & 316.6 & 2.63 \\
\hline
\end{tabular}

$h=31.7 \mathrm{~mm}(\lambda / 30), p x m=p x p=100 \mathrm{~mm}, p y m=50 \mathrm{~mm}, p y p=300 \mathrm{~mm}, h y=10 \mathrm{~mm}$.
TABLE II. RETURN LOSS BANDWISTH AND DIRECTIVITY FOR DIFFERENET $h y$.

\begin{tabular}{|c|c|c|c|c|c|}
\hline \multirow{2}{*}{$\begin{array}{c}h y \\
{[\mathrm{~mm}]}\end{array}$} & \multirow{2}{*}{$\begin{array}{c}\text { hy4 } \\
{[\mathrm{mm}]}\end{array}$} & \multirow{2}{*}{$\begin{array}{c}\mathrm{L2} \\
{[\mathrm{mm}]}\end{array}$} & \multicolumn{2}{|c|}{$\begin{array}{c}\text { Return loss bandwidth } \\
{[\mathrm{MHz}]}\end{array}$} & \multirow{2}{*}{$\begin{array}{c}\text { Direcitivity } \\
\text { at } 315 \mathrm{MHz} \\
{[\mathrm{dBi}]}\end{array}$} \\
\hline & & & Lower freq. & $\begin{array}{l}\text { Higher } \\
\text { freq. }\end{array}$ & \\
\hline 6 & 149 & 203.1 & 311.4 & 315.7 & 3.08 \\
\hline 10 & 141.7 & 196.3 & 311.4 & 315.7 & 3.02 \\
\hline 14 & 137.5 & 192 & 311.5 & 315.8 & 2.99 \\
\hline
\end{tabular}

$h=31.7 \mathrm{~mm}(\lambda / 30), p x m=p x p=100 \mathrm{~mm}, p y m=50 \mathrm{~mm}, p y p=300 \mathrm{~mm}, h x=20 \mathrm{~mm}$.

TABLE III. RETURN LOSS BANDWISTH AND DIRECTIVITY FOR DIFFERENET $p x m=p x p$

\begin{tabular}{|c|c|c|c|c|c|}
\hline \multirow{2}{*}{$\begin{array}{l}\text { pxm= } \\
\text { pxpy } \\
{[\mathrm{mm}]}\end{array}$} & \multirow{2}{*}{$\begin{array}{l}\text { hy4 } \\
{[\mathrm{mm}]}\end{array}$} & \multirow{2}{*}{$\begin{array}{c}L 2 \\
{[\mathrm{~mm}]}\end{array}$} & \multicolumn{2}{|c|}{$\begin{array}{l}\text { Return loss bandwidth } \\
{[\mathrm{MHz}]}\end{array}$} & \multirow{2}{*}{$\begin{array}{c}\text { Direcitivity } \\
\text { at } 315 \mathrm{MHz} \\
{[\mathrm{dBi}]}\end{array}$} \\
\hline & & & Lower freq. & $\begin{array}{l}\text { Higher } \\
\text { freq. }\end{array}$ & \\
\hline 100 & 141.7 & 196.3 & 311.4 & 315.7 & 3.02 \\
\hline 60 & 126 & 199.4 & 310.1 & 317.4 & 2.86 \\
\hline 35 & 109.5 & 197.5 & 309.2 & 318.6 & 2.55 \\
\hline
\end{tabular}

$h=31.7 \mathrm{~mm}(\lambda / 30)$, pym $=50 \mathrm{~mm}$, pyp $=300 \mathrm{~mm}, h x=20 \mathrm{~mm}, h y=10 \mathrm{~mm}$.

TABLE IV. RETURN LOSS BANDWISTH AND DIRECTIVITY FOR DIFFERENET $p y p$.

\begin{tabular}{|c|c|c|c|c|c|}
\hline \multirow{2}{*}{$\begin{array}{c}\text { pyp } \\
{[\mathrm{mm}]}\end{array}$} & \multirow{2}{*}{$\begin{array}{c}\text { hy4 } \\
{[\mathrm{mm}]}\end{array}$} & \multirow{2}{*}{$\begin{array}{c}\mathrm{L2} \\
{[\mathrm{mm}]}\end{array}$} & \multicolumn{2}{|c|}{$\begin{array}{c}\text { Return loss bandwidth } \\
{[\mathrm{MHz}]}\end{array}$} & \multirow{2}{*}{$\begin{array}{c}\text { Direcitivity } \\
\text { at } 315 \mathrm{MHz} \\
{[\mathrm{dBi}]}\end{array}$} \\
\hline & & & Lower freq. & $\begin{array}{l}\text { Higher } \\
\text { freq. }\end{array}$ & \\
\hline 300 & 141.7 & 196.3 & 311.4 & 315.7 & 3.02 \\
\hline 260 & 153 & 194 & 312.2 & 314.7 & 2.42 \\
\hline 220 & 161 & 192.9 & 312.8 & 314.3 & 1.54 \\
\hline
\end{tabular}

TABLE V. RETURN LOSS BANDWISTH AND DIRECTIVITY FOR DIFFERENET $p y m$

\begin{tabular}{|c|c|c|c|c|c|}
\hline \multirow{2}{*}{$\begin{array}{c}\text { pym } \\
{[\mathbf{m m}]}\end{array}$} & \multirow{2}{*}{$\begin{array}{c}\text { hy4 } \\
{[\mathbf{m m}]}\end{array}$} & $\begin{array}{c}\text { L2 } \\
{[\mathbf{m m}]}\end{array}$ & \multicolumn{2}{|c|}{$\begin{array}{c}\text { Return loss bandwidth } \\
{[\mathbf{M H z}]}\end{array}$} & $\begin{array}{c}\text { Direcitivity } \\
\text { at 315MHz } \\
\text { [dBi] }\end{array}$ \\
\hline 50 & 141.7 & 196.3 & 311.4 & 315.7 & 3.02 \\
\hline 30 & 141.5 & 195.9 & 311.4 & 315.7 & 2.94 \\
\hline 10 & 141 & 195.5 & 311.5 & 315.7 & 2.87 \\
\hline
\end{tabular}

$h=31.7 \mathrm{~mm}(\lambda / 30), p x m=p x p=100 \mathrm{~mm}, p y p=300 \mathrm{~mm}, h x=20 \mathrm{~mm}, h y=10 \mathrm{~mm}$.

\section{B. Miniaturized model}

Due to the parameter study, the miniaturized model is decided. The parameters of miniaturized antenna are as follows. $h=31.7 \mathrm{~mm}(\lambda / 30)$, hy $4=107 \mathrm{~mm}, L 2=196.2 \mathrm{~mm}$, $h x=20 \mathrm{~mm}, h y=10 \mathrm{~mm}$, pxm $=100 \mathrm{~mm}$, pxm $=$ pxp $=35$ $\mathrm{mm}$, pym $=50 \mathrm{~mm}$, pyp $=300 \mathrm{~mm}$.

Figure 6 shows the current distribution of the miniaturized antenna with one-turn meander line. The surface current is suppressed between the base point of antenna and the edge of conducting plane $y=-p y m$. Figure 7 shows the return loss characteristics. Figure 8 shows the electric field radiation patterns at the frequency of $315 \mathrm{MHz}$. The directivity of this antenna becomes $2.48 \mathrm{dBi}$ at the frequency of $315 \mathrm{MHz}$. 


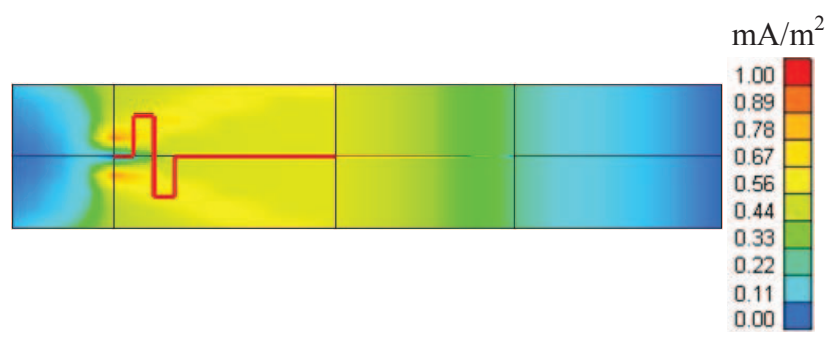

Figure 6. Current distribution of miniaturized antenna at $315 \mathrm{MHz}$.

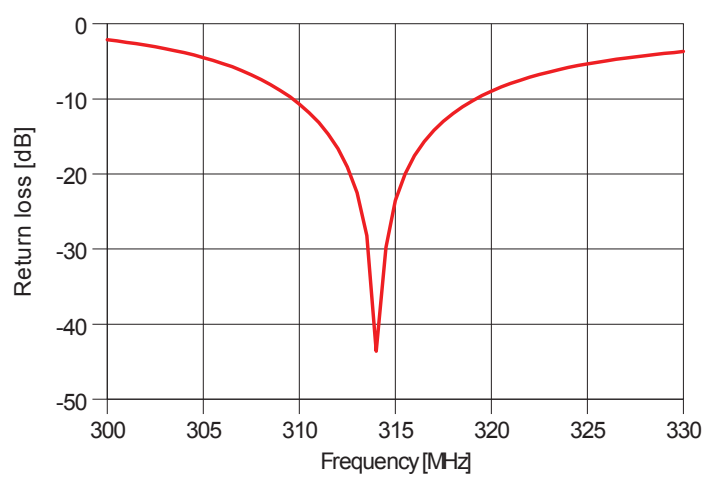

Figure 7. Return loss characteristics of miniaturized antenna.

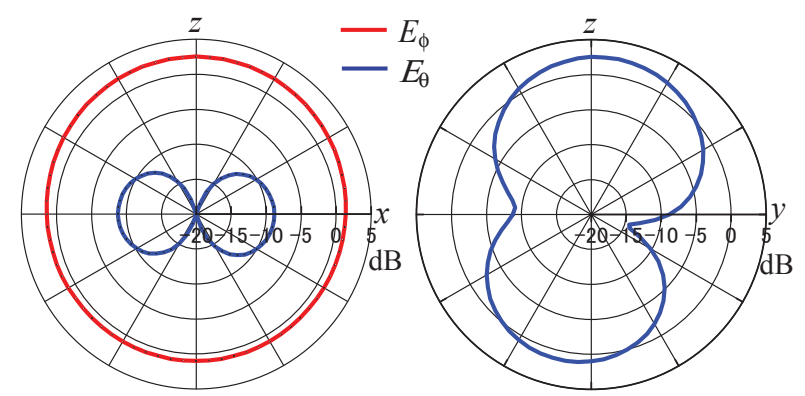

Figure 8. Electric field radiation patterns of miniaturized antenna at $315 \mathrm{MHz}$.

\section{CONCLUSION}

The ultra low profile inverted L antenna, whose horizontal element is bent as a meander line shape, has been proposed for the reception antenna for the keyless entry system of automobiles at $315 \mathrm{MHz}$ band. In the case of the conducting plane of $70 \mathrm{~mm}$ by $350 \mathrm{~mm}$ and the antenna height of $31.7 \mathrm{~mm}$, the directivity of $2.48 \mathrm{dBi}$ is obtained. The comparison between the calculated and measured results of this antenna will be shown at the conference.

\section{REFERENCES}

[1] http://www.omron.co.jp

[2] M. Taguchi, Y. Sanabe and Y. Hamada: "Numerical analysis of electromagnetic field distribution in hollow metallic rectangular parallelepiped with roof", Proc. of 2007 Korea-Japan Microwave Conference, pp.29-32, Nov. 2007.

[3] M. Taguchi, Y. Sanabe and Y. Hamada: "Numerical analysis of electromagnetic field distribution in hollow metallic rectangular parallelepiped with roof -Part 2-", Proc. of 2009 Korea-Japan Microwave Conference, pp.77-80, April 2009.

[4] T. Yamashita and M. Taguchi: "Ultra low profile inverted L antenna on a finite conducting plane", Proc. of 2009 Int. Symp. on Antennas and Propagation, Bangkok, pp. 361-364, Oct. 2009.

[5] http://www.wipl-d.com. 